\title{
Comparative analysis of PIA and rSesC mixture, as vaccine candidate against the biofilm forming Staphylococcus aureus.
}

\section{Bahman Mirzaei ( $\nabla$ dr.bahman.m@gmail.com )}

Zanjan university of medical sciences

\section{Ryhane Babaei}

Zanjan University of Medical Sciences

Fatemeh Mohammadi

Zanjan University of Medical Sciences

\section{Hamid Reza Goli}

Mazandaran University of Medical Sciences

\section{Sanaz Amir Gholami}

Mazandaran University of Medical Sciences

\section{Sarah Bahonar}

Mazandaran University of Medical Sciences

\section{Mohammad Reza Haghshenas}

Mazandaran University of Medical Sciences

\section{Research article}

Keywords: PIA and rSesC, Mixture vaccine candidate, Biofilm formation, Staphylococcus aureus

Posted Date: August 26th, 2019

DOI: https://doi.org/10.21203/rs.2.12728/v1

License: (c) (i) This work is licensed under a Creative Commons Attribution 4.0 International License. Read Full License 


\section{Abstract}

Background: Staphylococcus aureus as a causative agent of hospital-acquired infections, has been considered as the primary concern in biomaterial-related infections (BAls). Methods: Following the purification of polysaccharide intercellular adhesion (PIA) as an efficient macromolecule in biofilm formation in the native condition, recombinant $\mathrm{S}$. epidermidis surface exposed $\mathrm{rSesC}$ protein, with the most homology to clumping factor $\mathrm{A}$ (ClfA) in S. aureus was cloned and expressed in a prokaryotic host as well. Fourier transform infrared spectrometry (FTIR) and Western blotting procedure analyzed purified PIA and protein, respectively. Then, the immune response was evaluated by measuring total IgG titers. Moreover, the capacity of Anti-biofilm forming activity of arisen antibodies to a biofilm forming S. aureus strains was assessed by semi-quantitative micro-plate procedure. Results: Data showed that the total IgGs was boosted in mice immunized sera. By performing inhibition assay, biofilm inhibitory effect of secreted antibodies to test strain was observed. Arisen antibodies against the mixture significantly were more potent than PIA and $\mathrm{rSesC}$, when comparing them in a biofilm inhibition assay.

\section{Background}

Staphylococci, are opportunistic pathogens and determined as most common causes of infections related to implanted medical devices, infects both hospitalized patients and immunocompromised individuals [1].Considering diverse virulence factors, such as both capsule and cell wall-bound adhesion molecules, surface proteins, toxins, antibiotic resistance, and biofilm formation S. aureus could be make human and animal related infections. [2]. S. aureus is an etiological agent of the mild to severe related hospitalized patiense disorders including skin and tissue, bacteremia complicated by endocarditis, pneumonia, and metastatic infections. Finding reveled that, almost main part of adults are either permanently or transiently colonized by $S$. aureus due to the some discovered factors that makes the host susceptible for colonization.3] Up to $20-30 \%$ of humans, asymptomatically are colonized by S. aureus and $50-60 \%$ of those are intermittently colonized $[4,5]$ Since the 1960 s, first (MRSA) strains were detected and then they have been spreading worldwide, becoming a global major challenge. Despite the importance of mentioned bacterium in human and animal infections, there are no available vaccines to prevent $S$. aureus relatedinfections yet [6]. Contamination of medical devices with $S$. aureus during insertion might be remarkably depended on the patient health care personal. Although there are some similarity in biofilm-associated infections with $S$. aureus and $S$. epidermidis, usually more intensive care is needed for the involvement of $S$. aureus In comparison with $S$. epidermidis biofilm-associated infections, not only $S$. aureus biofilm-associated infections are more difficult to be treated by antibiotic therapy, but also the devices need to get replaced more frequently [7]. The ica operon of staphylococcus spp, encode the production of polysaccharide intercellular adhesin (PIA), also known as poly-N-acetyl glucosamine (PNAG) [8]. The PIA-dependent mechanism is the best understood mechanism of biofilm formation. Cerca et al. demonstrated that rabbit anti-PIA antibodies protect against infections with planktonic cells of PIA-positive S. aureus and S. epidermidis [9]. Based on a study by Maira-Litran et al., anti-dPIA antibodies mediated opsonic killing and protected against $S$. aureus infection [10]. Recent studies 
indicate other proteinaceous mechanisms of biofilm formation may exist. Shahrooei revealed that monoclonal antibodies against $S$. epidermidis surface-exposed Ses proteins can significantly reduce the accumulation phase [11]. Clumping factor $\mathrm{A}$ (ClfA) is a fibrinogen $(\mathrm{Fg})$-binding microbial surface molecule recognizing adhesive matrix molecules (MSCRAMM) of $S$. aureus; $65.1 \%$ similarity has been shown between SesC and a 341-aa fragment of ClfA [12].

Owing to the vital biofilm forming capacity role in the chronic staphylococcal disease development, evaluation of the biofilm inhibitory effect of PIA and recombinant SesC antibodies against a biofilm forming $S$. aureus, separatelyand in mixturewas targeted as the main goal of this study.

\section{Results}

\section{Purification of macromolecules:}

Basing on the cloning and expression procedure, 1399 bp encoding gene of 55KD recombinant protein representative of $\mathrm{rSesC}$ was cloned in $\mathrm{pET} 11 \mathrm{C}$ vector and transformed to the BL21 (DE3) as a prokaryotic host. The expressed protein was purified taking advantage of affinity chromatography procedure as well. Representative rSesC protein was confirmed basing on the size by SDS- PAGE procedure. Then presence of a C-terminal hexa-His- tagged residue in the protein was determined by a Western blot Following the Bradford assay procedure. Amount of the purified protein was assessed about 5mg. Fig.1.

\section{Purification of PIA}

PIA as a main compartment of biofilm forming macromolecule in aggregation phase was purified basing on the native condition procedure using size exclusion chromatography procedure. To isolate PIA (100 $K D$ ), size-exclusion chromatography was performed by Sephacryl S-100. PIA was purified at a flow rate of $0.300 \mathrm{ml} \mathrm{min}-1$ and fractions of $1.5 \mathrm{ml}$ were collected every $5 \mathrm{~min}$ in a fraction collector. Contaminated PIA by proteins and nucleic acid (RNA and DNA) was cleaned by enzymatic digestion too. Chemical analysis of purified PIA indicated negligible contamination ( $<2 \%$ protein and $<0.4 \%$ nucleic acid). Subsequently basing on the colorimetric assay procedure by targeting the $\mathrm{N}$-acetyl Glucosamine residue in the compartment, data showed that the purified PIA contained $65 \%$ hexosamine $(5700 \mu \mathrm{g}$ $\mathrm{ml}-1)$, uronic acid $(29 \mu \mathrm{g} \mathrm{ml}-1)$ and ketose $(170 \mu \mathrm{g} \mathrm{ml}-1)$. The composition and structure of the PIA were confirmed by using FTIR procedure too. Fig. $2-4$.

\section{Endotoxin contents and general safety}

According to the Limulus amebocyte lysate test to purified macromolecules, the content of endotoxin was determined as $4.5 \mathrm{EU} \mathrm{ml}-1$. Pyrogenicity and toxicity were not observed following in vivo challenge.

\section{Anti-antigens humoral response}

Using antigen mediated ELISA in order to evaluate the total IgG antibody response against PIA in the mixture antigen, mice sera antibodies titers were determined $(\leq 1: 200)$. Following the first immunization 
by rSesC and PIA ( $P=0.0057)$ low level IgGs production comparing to the control group was observed and this amount determined as not significant to rSesC immunized sera. An increase in IgG titres to PIA $(P=0.0004)$ and $\operatorname{rSesC}(P=0.0025)$ was observed following the first booster. The third group of mice received a mixture of PIA and rSesC and an increase in anti-PIA antibodies was observed following the second immunization $(P<0.0001)$. Fig. 5.

\section{Biofilm inhibition assay by microtiter plate}

The biofilm inhibition assay was performed by comparing pre-post immune sera by semi-quantitative procedure. Experiments were observed with sera from mice that were boosted after specific time spans $(14,28$ and 42 days) and results were obtained by comparing the immunized and non-immunized sera, respectively. (Fig. 6). The data showed that those mice immune sera which immunized by PIA antigen provide significant ( $P>0.05$ ) inhibition after first booster dosage. The inhibitory effects of sera after first boosted sera with rSesC $(P>0.0314)$ after first boosted the PIA/rSesC mixture, $(P>0.0015)$ and after the second booster were also significant. Observed data showed that, vaccinated sera two weeks haven't significant biofilm inhibitory effect after the first immunization (14 days) by PIA and rSesC antigens compared to the control group. However, this effect for sera which immunized by PIA/rSesC mixture $(P=$ 0.0004) was significant when compared by the control sera. Detailed OD average listed in table 1.

\section{Methods}

\section{Bacterial strains:}

Purification of the PIA and related procedure were accomplished applying two biofilm-forming $S$. epidermidis strains, ATCC 14990 and 35984, also known as 1457 and RP62A, a transmutant strain, 1457M10 and a wild type biofilm forming S. aureus strain, too. Moreover, Escherichia coli strain BL21 (DE3) was served as prokaryotic host to DNA manipulation and recombinant protein production.

\section{Construction and purification of His-tagged rSesC protein}

Based on the previously reported procedure, [12] a 1,359-bp fragment of SesC encoding a 459aa extracellular part of SesC containing a six-His-tag at the C-terminus was amplified. In short, following the cloning and expression of the representative sequence in a prokaryotic host, 55KD rSesC protein was determined by SDS-PAGE and Coomassie Brilliant Blue staining. Protein was expressed in Eshershia coli BL21 DE3 following the induction by $1 \mathrm{mM}$ imidazole in optical density $0.7-$ 0.9 in a shaker incubator ( $150 \mathrm{rpm}$ in $37^{\circ} \mathrm{C}$ for 3 hours). Purifying the recombinant protein was done using the commercial affinity chromatography Kit (GE health care, Sweden) according to the manufacture's recommendation followed by extraction of soluble protein from induced host using sonication (4 times for $30 \mathrm{~s}$ on ice) with an additional centrifugation (12 000 r.p.m. for 20 min at $4{ }^{\circ} \mathrm{C}$ ) to the clarification of the targeted protein. The purity of the recombinant protein was determined by Coomassie blue staining of a sodium dodecyl sulfate-polyacrylamide gel electrophoresis gel and then analyzed by western blotting. The expression of the protein was done as follows: E. coli BL21 (DE3) 
cells were transformed with the vector. Cells were grown with shaking at $250 \mathrm{rpm}$ at $37^{\circ} \mathrm{C}$ in Luria-Bertani broth with $100 \mathrm{~g} / \mathrm{ml}$ ampicillin to an optical density at $600 \mathrm{~nm}$ of 0.6 to 0.8 . Isopropyl-Dthiogalactopyranoside (IPTG) in $1 \mathrm{mM}$ as a final concentration was added on media to induction of protein expression. Following cooling on ice, cells were collected by centrifugation at 8,000 rpm for $5 \mathrm{~min}$ at $4{ }^{\circ} \mathrm{C}$, resuspended in imidazole buffer, and frozen at $-20^{\circ} \mathrm{C}$. Harvested pellets was sonicated three times for $30 \mathrm{~s}$ on ice. The expressed protein was determined by SDS-PAGE and coomassie brilliant blue staining (Fig. 1).

\section{Extraction and purification of native PIA}

PIA was purified as previously described $[13,14]$. Briefly, the cells were harvested from incubated $\left(37^{\circ} \mathrm{C}\right.$ for $24 \mathrm{~h}$ with shaking at $40-50 \mathrm{rpm} / \mathrm{min}) 2$ liters of trypticase soy broth (TSB) by centrifugation $(4,500$ $\mathrm{rpm}$ for $20 \mathrm{~min}$ at $4{ }^{\circ} \mathrm{C}$ ) and were re-suspended in $20 \mathrm{ml}$ of $50 \mathrm{mM}$ sodium phosphate buffer (pH 7.5). After that, the suspended colonies were sonicated four times for $30 \mathrm{~s}$ on ice. The extracts were cleaned up by centrifugation at $12,000 \mathrm{rpm}$ for $15 \mathrm{~min}$ at $4{ }^{\circ} \mathrm{C}$. The supernatant was dialyzed overnight in a $12 \mathrm{KD}$ dialysis bag against the same buffer and concentrated using Centriprep 10 (Amicon, Witten, Germany). The soluble proteins were eliminated by proteinase- $K$, and then sample was directly loaded onto an equilibrated $1.6 \times 100 \mathrm{~cm}$ Sephacryl S-100 column (Pharmacia LKB GmbH, Freiburg, Germany) with 50 $\mathrm{mM}$ sodium phosphate. At the end, purified PIA was stored at $-20{ }^{\circ} \mathrm{C}$ in Amicon cell (Fig. 2). The concentration of the purified PIA was assessed via the amount of hexosamine, taking advantage of the 3methyl-2-benzothiazolone hydra- zine hydrochloride method with $\mathrm{N}$-acetyl glucosamine as standard (see Fig. S1, which is available in the online version of this article) (18).

\section{Biochemical analysis}

The amount of protein content in the purified rSesC was assessed by the Bradford assay (17). The constitution and structure of the purified native PIA was analysed using Fourier transform infrared spectroscopy (FTIR) and colorimetric assays (Fig. 3, 4) as well.

\section{Pyrogenicity test and general safety}

Taking advantage of the previously procedure, the pyrogenicity and toxicity of the antigens were checked [15]. The amount of endotoxin in the prepared antigens was measured by a commercial Limulus amebocyte lysate kit (Thermo Scientific, Waltham, MA, USA) according to the manufacturer's recommendations.

\section{Immunization of mice}

6-8-week-old female 18 $\pm 2 \mathrm{~g} \mathrm{BALB/c} \mathrm{inbred} \mathrm{mice} \mathrm{(purchased} \mathrm{from} \mathrm{the} \mathrm{Research} \mathrm{Institution} \mathrm{of} \mathrm{Pasteur}$ Karaj, IR Iran) were divided into four groups of six mice each for the vaccination experiments. The mice were housed in standard stainless cages at $23-25^{\circ} \mathrm{C}$ and $60-70 \%$ humidity, with a $12 \mathrm{~h}$ light/dark cycle, for a week before the experience. The mice were given free access to a standard diet and water. Each mouse in the specific group was immunized thrice subcutaneously with the respective lyophilized 
antigens (PIA, rSesC, PIA/ rSesC, and PBS) in $1 \%$ alum (Brentag, Denmark) dissolved in PBS (filtered at $0.22 \mathrm{~nm}$ pore diameter). The quantity of candidate vaccines were adjusted to a concentration of PIA and protein in the mixture then an immunogenicity of candidate vaccines was compared to control. After two weeks of each immunization (immunization days were $0,7,14$ and 28) $500 \mu$ l of peripheral blood was collected from the tail vein of five mice in each group. Collected sera were stored at $-20^{\circ} \mathrm{C}$ followed by centrifugation (3000 r.p.m. for $5 \mathrm{~min}$ ) of peripheral blood [16].

The experimental groups were as follows:

G-I: PIA $(100 \mu g)$;

G-II: rSesC $(25 \mu \mathrm{g})$;

G-III: PIA/rSesC mixture $(75 / 25 \mu \mathrm{g})$;

G-V: PBS.

\section{Ethics statement}

All animal experiments were performed in accordance with the enlarged ethical statement and approved by Mazandaran University of Medical Sciences ethics committee All performed on the enlarged ethical statement IR.MAZUMS.REC.1397.55 meeting number in Mazandaran University of Medical Sciences. Inbred mice were purchased from the Research Institution of Pasteur, Karaj, Iran.

Using the halogenated ether procedure as an inhalant anesthetic, mice were euthanized as well.

Enzyme-linked immunosorbent assay (ELISA)

Anti-PIA antibodies were introduced into the immunized mice sera by applying a commercial enzymelinked immunosorbent assay after each immunization. Briefly, 96-well plates (Extra gene, USA) were coated overnight with $100 \mu \mathrm{l}$ of PIA $(1 \mu \mathrm{g} /$ well $)$ in PBS at $4{ }^{\circ} \mathrm{C}$. Then, the plates were washed three times with washing buffer [0.05\% (v/v) Tween 20 in PBS], followed by blocking with PBS/Tween 20 containing $5 \%$ bovine serum albumin (BSA) for $2 \mathrm{~h}$ at $37^{\circ} \mathrm{C}$. Fling blocking and washing, the mouse sera were (1: 2 to 1: 1024) in blocking buffer and $100 \mu$ of the samples was added to the wells in duplicate. The plates were incubated for $2 \mathrm{~h}$ at $37^{\circ} \mathrm{C}$, washed three times and incubated with HRP- conjugated anti-mouse IgG (Sigma, USA) diluted to $1: 10000$ (as a secondary antibody) at $37^{\circ} \mathrm{C}$ for $2 \mathrm{~h}$. The plates were washed as described above; enzymatic activity was measured by adding $100 \mu$ of tetramethylbenzidine (TMB) substrate.

After 30 min subjoining $100 \mu \mathrm{l}$ of $2 \mathrm{~N} \mathrm{H} 2 \mathrm{SO} 4$ the reaction was stopped. (Fig. 5).

In vitro biofilm inhibition assay 
Biofilm inhibitory effect ofpre- and post-immune IgGs against injected antigens on in vitro biofilm formation was analysed using a semi-quantitative microtiter plate method17]. (Fig. 6). In short, $5 \times 10^{5}$ c.f.u. $\mathrm{ml}^{-1}$ of an overnight culture of $S$. aureus grown in BHI for the initial attachment in fresh sterile trypticase soy supplemented by $1 \%$ glucose (TSBg) broth was prepared.

A while later, in a polystyrene microtiter plate (Corning Joined Life Sciences, Lowell, MA, USA), a mixture of $200 \mu \mathrm{l}$ of diluted bacterial cultures and $50 \mu \mathrm{l}$ of twofold diluted post and pre-immunized mouse sera were inoculated into three parallel wells. After incubation at $37^{\circ} \mathrm{C}$ for $20 \mathrm{~h}$, respectively, the attached cells and biofilm were stained by crystal violet as previously described [18]. The OD at 595 (OD595) of the dissolved stain in $160 \mu \mathrm{l}$ of $30 \%(\mathrm{vol} / \mathrm{vol})$ acetic acid was measured in a multipurpose UV/VIS plate reader. A negative control of sterile TSBg without bacteria was included and the assay was repeated independently three times. A previously described in vitro biofilm formation assay previously described was also performed[18].

The percentage inhibition of biofilm formation was calculated using the following formula:

(A 595, positive -A 595, antibody) / (A 595, positive - A 595, negative) ×100 [18].

Statistical analysis

Utilizing multiple- group analysis of variance (ANOVA), statistical analysis of results was accomplished and a P-value $<0.05$ was considered significant.

Abbreviations: Not applicable

\section{Discussion}

S. aureus as a main human primary pathogen because of the ability to biofilm formation and antibiotic resistance pattern has been assigned as an essential concern in worldwide healthcare system [19]. Staphyloccocus species specially $S$. aureus and $S$. epidermidis despite being a part of human flora,wellknown ability to attach to surfaces of medical devices and develop into recalcitrant community multilayered structures, referred to as "biofilm", makes them problematic [20]. Biofilm forming ability is a surveillance factor in Staphyloccocus spp., mediating the adherence of bacterial cells to biomaterials and helps organisms to avoid the host immune defense [21]. Staphylococcalability to form biofilm, considered the most important factor involved in the pathogenesis, and its colonization on medical devices, makes it increasingly resistant not only to multiple antibiotics but also to host defenses. There is an essential need to replace the medical devices after $S$. epidermidis biofilm infection, and practical studies on biofilm-preventing vaccines is necessary as well [22]. The role of PIA and proteins in biofilm formation has been clearly demonstrated. Targeting of the SesC protein and PIA macromolecules involved in attachment and accumulation biofilm forming phase's and antibodies that arise in response to them may be suitable options for antibodies-dependent treatment of biofilms [21]. In the current study, the evaluation of arisen antibodies against PIA and rSesC protein, efficacy of antibodies to biofilm 
inhibition process and putative vaccine candidate activity against the mentioned antigens of $S$. aureus have been listed as the main purposes. Taking advantage of cloning, rSesC protein was generated and confirmed with precision by Western blotting procedure. The DNA sequence of the truncated protein representative of the anchor site on the SesC protein was inserted into cloning vector and transformed into the prokaryotic host. 55KD protein representative of rSesC previously purified $[12,23]$. Our results were confirmed when compared by mentioned studies. Less than $70 \%$ similarity described to homologous proteins. Although, the specific function of the SesC proteins hadn't describe, but the closest homologous protein to $\mathrm{SesC}$, is a 341 aa fragment nominated Clumping factor $\mathrm{A}$ in $\mathrm{S}$. aureus with specific function(Identity $26.6 \%$ and Homology $65.11 \%$ ) [12].

Reported data by previously published demonstrate that the arisen antibody to immunized animals with conjugated a deacetylated PNAG ( $\leq 15 \%$ acetyl) to diphtheria toxoid (DT) as a carrier protein shown a killing activity against three strains of $S$. aureus and a PIA dependent biofilm forming S. epidermidis M187 [14].

Because of this homology, biofilm inhibitory effect of the arisen antibodies to rSesC was targeted to biofilm forming $S$. aureus. Based on the results, $\mathrm{rSesC}$ protein has been determined as the suitable biofilm inhibitory candidate vaccine following the injection of $25 \mathrm{mg} / \mathrm{ml}$ of the mentioned antigens in mice. This protein not only caused to arise the specific antibodies after the first booster, but also biofilm inhibitory effect of raised antibodies was confirmed. Despite that raised mentioned antibodies were not significant when compared to the first immunization (14/28 days) but the amount of arisen antibodies when compared to the second booster was significantly increased. Raised antibodies against rSesC protein, as a $S$. aureus clumping factor A protein homolog, successfully decreased biofilm formation in a biofilm forming wild type $S$. aureus comparing the collected sera after injection times. Our results showed that rSesC, due to the biofilm inhibitory effect, separately could be a vaccine candidate in biofilm forming $S$. aureus, too. Taking advantage of reported findings [25], although rSesC and PIA were described as two effective vaccine candidates in biofilm forming $S$. epidermidis, the conjugation of PIA to rSesC will enhance the opsonic activity of secreted antibodies, too. In this study, a mixture of rSesC and PIA was prepared and arisen antibodies of mixture against biofilm forming wild type $S$. aureus were assessed. Findings support the hypothesis that rSesC could be hopefully considered as a suitable candidate vaccine against biofilm forming $S$. aureus, too.

PIA as the main component of bacterial accumulation during biofilm formation, was extracted from wildtype strain 1457 basing on the native purification process [13]. The composition of purified PIA confirmed by FTIR and it was observed that our data and other published data are similar [13, 21]. We tried to evaluate the PIA and rSesC efficacies as immunoprophylaxis and immunotherapy against biofilmforming S. aureus. According the previous studies, the purity of native purified PIA can elicit an antibody response against the mentioned antigen [20,24-26]. Although the antigenicity of most polysaccharides is poor, increased antibodies to PIA have shown a biofilm inhibitory effect. Corresponding antigens had previously been analysed as a useful candidate vaccine against biofilm-forming $S$. epidermidis, but the opsonic rate of the rSesC protein was lower in purified IgGs [21]. 
At the present research, 6-8 weeks female mice were immunized by PIA, rSesC and mix of them in four categorized. Control group received PBS as basic solvent of antigens. All mice were boosted by each specific antigens two weeks after first immunization. Immunized sera were collected in 14, 28 and 42 days after the first immunization. According to the obtained results in ELISA, to evaluation of the total IgGs by checker board method, diluted sera in 1:200 determined as titers for all of the antigens. PIA and rSesC Immunized sera were not statistically significant when compared by the control 14 days after the first immunization. After the first booster dosage, increasing of the PIA and $\mathrm{rSesC}$ antibodies titers were observed, while titers of arisen antibodies in $28(P=0.0025)$ and $42(P=0.0001)$ collected immune sera were statistically significant. Arisen antibodies to mixture of PIA and rSesC in all immunized sera were statistically significant. Similar results were observed in previously published study based on the antigenicity of mentioned macromolecules [21].

Regarding the results reported in previous studies, the presence of amine groups in the PIA structure arisen titers in the first and second boosters is justifiable. The alum as an adjuvant could be stimulated the secreted antibodies and induction of Th2 immunity as well.

Since one of the most important characteristics of vaccine candidates is the in vitro and in vivo effects of them, in this study, the features of polyclonal secreted antibodies analysed on biofilm formation under laboratory conditions. Data showed that, immune sera after 14 days had biofilm inhibitory effect, however after the first and second reminders, the effect of biofilm inhibition in the mixture group and other groups showed a significant difference compared with the control group in the last reminder. Efficacy of arisen antibodies in immunized sera showed that, at the first immunization for PIA ( $P=$ $0.3466)$, rSesC $(P=0.371)$, biofilm inhibitory effect were not statistically significant when compared by the control group. Immunized sera by mix of PIA and rSesC in two week after the first immunization showed the biofilm inhibitory effect was statistically significant $(P=0.0004)$. Biofilm inhibitory effect of antigens comparing the different immunization era (14/28 days) showed that the immunized sera by PIA, rSesC $(P=0.0314)$ and Mix of them $(P=0.0003)$ were statistically significant as well.

Previous researches reported that the mixture of mentioned macromolecules had a good biofilm inhibitory effect. Our published study [25] reported that using a mixture of PIA and rSesC, the opsonic activity of arisen antibodies enhanced against biofilm forming S. epidermidis [25]. In this study, biofilm inhibition capability to PIA/rSesC mixture antibodies against biofilm forming $S$. aureus was evaluated. Although opsonic activity and in vivo challenge for survival not cheeked at the current research but biofilm inhibition assay demonstrated that mixture of PIA and $\mathrm{rSesC}$, because of suitable decreasing of the biofilm against a wild type biofilm forming $S$. aureus, could be considered as a good candidate vaccine regarding inhibition of biofilm formation in both $S$. epidermidis an $S$. aureus.

\section{Conclusions}

We found that a PIA/rSesC mixture vaccine could inhibit biofilm-formation process in biofilm producer $S$. aureus by eliciting high titer anti-PIA antibodies. It seems that this mixture could be employed for patients 
from the colonization and biofilm formation of mentioned bacterial. According to our findings, the immunization of high-risk patients with mixture of vaccine candidate or treatment of them using monoclonal antibodies such as IgG2a could help to eradicate bacterial biofilms. The preparation and purification of specific anti-PIA IgG2a are a possible means to inhibit medical device infections caused by S. epidermidis and $S$. aureus.

\section{Declarations}

\section{Ethics approval and consent to participate:}

This study was approved by Mazandaran University of Medical Sciences ethics committee All performed on the enlarged ethical statement IR.MAZUMS.REC.1397.55 meeting number in Mazandaran University of Medical Sciences. In this study, all ethics including Ethics and Consent to participate from their parents have been collected in the research.

\section{Consent for publication:}

Not applicable

\section{Availability of data and material:}

All the results of this study have been classified and maintained by the dissertation in the Pasteur Institute of Iran. We have indeed provided all raw data on which our study is based.

\section{Competing Interests:}

The authors declare that they have no competing interests.

\section{Authors' contributions:}

All authors read and approved the manuscript.

Contributions of the authors in this study was as follow:

B M: Designing the study, interpretation of results and writing the manuscript.

R B: Perform laboratory tests performing.

H R G: Performing laboratory tests

S A G: Biofilm inhibition assay and PIA purification 
S B: Performing laboratory test.

F M: Proof reading

M R H: Interpretation of results.

\section{Funding:}

Not applicable.

\section{Acknowledgement}

The authors wish to acknowledge Pasteur Institute of Iran for funding. The authors are grateful for the support of colleagues in Bacteriology and Venom Departments in Pasteur Institute of Iran.

\section{Conflict of Interest:}

The authors announce that they have no difference of interest.

\section{References}

1.Lindsey EA, Brackett CM, Mullikin T, Alcaraz C, Melander C: The discovery of N-1 substituted 2aminobenzimidazoles as zinc-dependent S. aureus biofilm inhibitors. MedChemComm 2012, 3(11):1462-1465.

2.Liu GY: Molecular pathogenesis of Staphylococcus aureus infection. Pediatric research 2009, 65(5):71R.

3.van Belkum A: Staphylococcal colonization and infection: homeostasis versus disbalance of human (innate) immunity and bacterial virulence. Current opinion in infectious diseases 2006, 19(4):339-344.

4.Hogea C, Van Effelterre T, Cassidy A: A model-based analysis: what potential could there be for a S. aureus vaccine in a hospital setting on top of other preventative measures? BMC infectious diseases 2014, 14(1):291.

5.Jones SM, Morgan M, Humphrey TJ, Lappin-Scott $\mathrm{H}$ : Effect of vancomycin and rifampicin on meticillinresistant Staphylococcus aureus biofilms. The Lancet 2001, 357(9249):40-41.

6.Adhikari RP, Karauzum H, Sarwar J, Abaandou L, Mahmoudieh M, Boroun AR, Vu H, Nguyen T, Devi VS, Shulenin S: Novel structurally designed vaccine for S. aureus a-hemolysin: protection against bacteremia and pneumonia. PLoS One 2012, 7(6):e38567. 
7.Kuklin NA, Clark DJ, Secore S, Cook J, Cope LD, McNeely T, Noble L, Brown MJ, Zorman JK, Wang XM: $A$ novel Staphylococcus aureus vaccine: iron surface determinant $B$ induces rapid antibody responses in rhesus macaques and specific increased survival in a murine $S$. aureus sepsis model. Infection and immunity 2006, 74(4):2215-2223.

8.Paharik AE, Horswill AR: The staphylococcal biofilm: adhesins, regulation, and host response. Microbiology spectrum 2016, 4(2).

9.Cerca N, Jefferson KK, Oliveira R, Pier GB, Azeredo J: Comparative antibody-mediated phagocytosis of Staphylococcus epidermidis cells grown in a biofilm or in the planktonic state. Infection and immunity 2006, 74(8):4849-4855.

10.Maira-Litrán T, Kropec A, Goldmann DA, Pier GB: Comparative opsonic and protective activities of Staphylococcus aureus conjugate vaccines containing native or deacetylated staphylococcal poly-N-

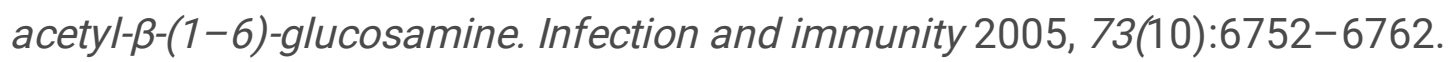

11.Shahrooei M, Hira V, Khodaparast L, Khodaparast L, Stijlemans B, Kucharíková S, Burghout P, Hermans PW, Van Eldere J: Vaccination with SesC decreases Staphylococcus epidermidis biofilm formation. Infection and immunity 2012:IAI. 00104-00112.

12.Shahrooei M, Hira V, Stijlemans B, Merckx R, Hermans PW, Van Eldere J: Inhibition of Staphylococcus epidermidis biofilm formation by rabbit polyclonal antibodies against the SesC protein. Infection and immunity 2009, 77(9):3670-3678.

13.Mirzaei B, Moosavi SF, Babaei R, Siadat SD, Vaziri F, Shahrooei M: Purification and evaluation of polysaccharide intercellular adhesion (PIA) antigen from staphylococcus epidermidis. Current microbiology 2016, 73(5):611-617.

14.Mack D, Nedelmann M, Krokotsch A, Schwarzkopf A, Heesemann J, Laufs R: Characterization of transposon mutants of biofilm-producing Staphylococcus epidermidis impaired in the accumulative phase of biofilm production: genetic identification of a hexosamine-containing polysaccharide intercellular adhesin. Infection and immunity 1994, 62(8):3244-3253.

15.Farjah A, Owlia P, Siadat SD, Mousavi SF, Ardestani MS, Mohammadpour HK: Immunological evaluation of an alginate-based conjugate as a vaccine candidate against Pseudomonas aeruginosa. Apmis 2015, 123(2):175-183.

16.Amini V, Kazemian H, Yamchi JK, Feyisa SG, Aslani S, Shavalipour A, Houri H, Hoorijani M, Halaji M, Heidari $\mathrm{H}$ : Evaluation of the Immunogenicity of Diphtheria Toxoid Conjugated to Salmonella Typhimurium-Derived OPS in a Mouse Model: A Potential Vaccine Candidate Against Salmonellosis. Iranian Red Crescent Medical Journal 2016, 18(7). 
17. Christensen GD, Simpson WA, Younger J, Baddour L, Barrett F, Melton D, Beachey E: Adherence of coagulase-negative staphylococci to plastic tissue culture plates: a quantitative model for the adherence of staphylococci to medical devices. Journal of clinical microbiology 1985, 22(6):996-1006.

18.Stepanović S, Vuković D, Hola V, BONAVENTURA GD, Djukić S, Ćirković I, Ruzicka F: Quantification of biofilm in microtiter plates: overview of testing conditions and practical recommendations for assessment of biofilm production by staphylococci. Apmis 2007, 115(8):891-899.

19.Kobayashi N, Taniguchi K, Kojima K, Urasawa S, Uehara N, Omizu Y, Kishi Y, Yagihashi A, Kurokawa I: Analysis of methicillin-resistant and methicillin-susceptible Staphylococcus aureus by a molecular typing method based on coagulase gene polymorphisms. Epidemiology \& Infection 1995, 115(3):419-426.

20.0tto M: Staphylococcus epidermidis-the'accidental'pathogen. Nature reviews microbiology 2009, 7(8):555.

21.Mirzaei B, Mousavi SF, Babaei R, Bahonar S, Siadat SD, Ardestani MS, Shahrooei M, Van Eldere J: Synthesis of conjugated PIA-rSesC and immunological evaluation against biofilm-forming Staphylococcus epidermidis. Journal of medical microbiology 2019, 68(5):791-802.

22.Hu J, Xu T, Zhu T, Lou Q, Wang X, Wu Y, Huang R, Liu J, Liu H, Yu F et al: Monoclonal antibodies against accumulation-associated protein affect EPS biosynthesis and enhance bacterial accumulation of Staphylococcus epidermidis. PloS one 2011, 6(6):e20918.

23.Shahrooei M, Hira V, Khodaparast L, Khodaparast L, Stijlemans B, Kucharíková S, Burghout P, Hermans PW, Van Eldere J: Vaccination with SesC decreases Staphylococcus epidermidis biofilm formation. Infection and immunity 2012, 80(10):3660-3668.

24.Krasowska A, Sigler K: How microorganisms use hydrophobicity and what does this mean for human needs? Frontiers in cellular and infection microbiology 2014, 4:112.

25.Marraffini LA, DeDent AC, Schneewind O: Sortases and the art of anchoring proteins to the envelopes of gram-positive bacteria. Microbiol Mol Biol Rev 2006, 70(1):192-221.

26.Christner M, Franke GC, Schommer NN, Wendt U, Wegert K, Pehle P, Kroll G, Schulze C, Buck F, Mack D: The giant extracellular matrix-binding protein of Staphylococcus epidermidis mediates biofilm accumulation and attachment to fibronectin. Molecular microbiology 2010, 75(1):187-207.

\section{Table 1}

Table 1. Average of mean optical density of representative sera to biofilm inhibition assay $(595 \mathrm{~nm})$.

Due to technical limitations, Table 1 is only available as a download in the supplemental files section. 


\section{Figures}

A

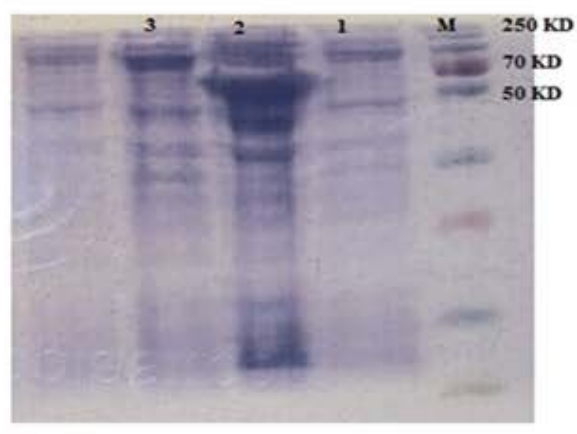

E

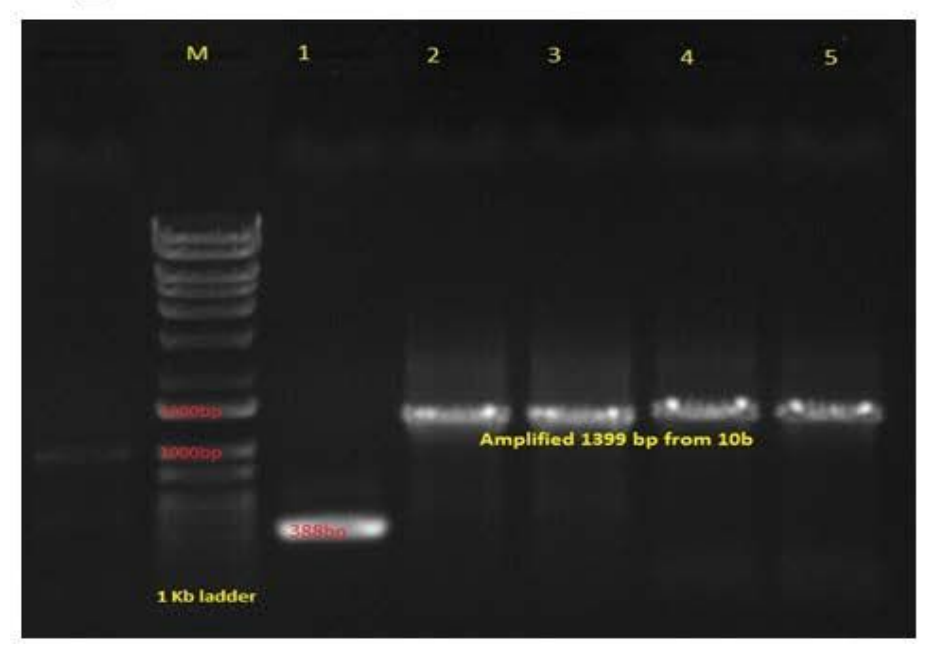

B c
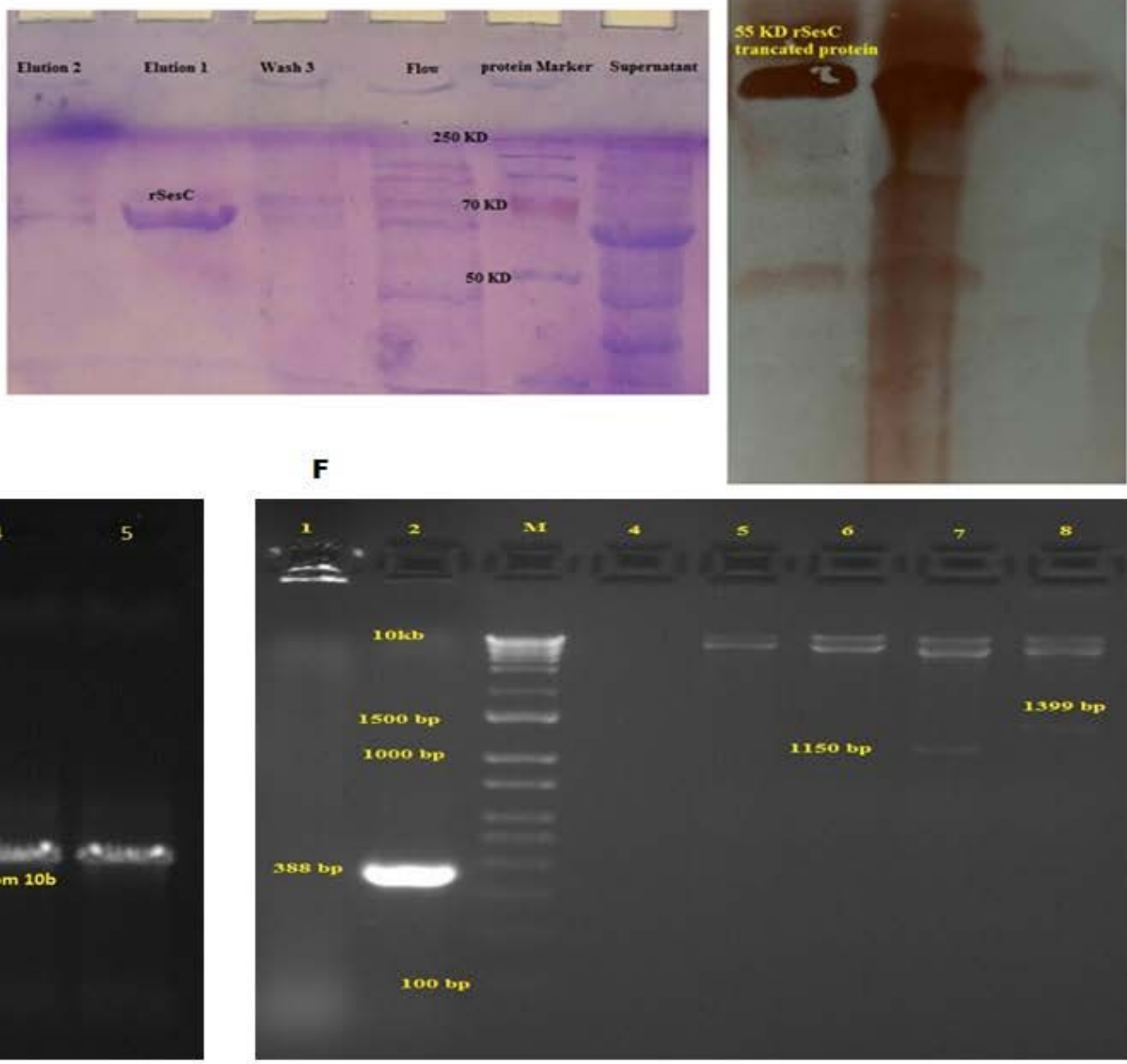

\section{Figure 1}

Construction and evaluation of rSesC protein. A) Confirmation of expressing protein after 3hrs by $1 \mathrm{mM}$ IPTG induction. 55KD bond representation of rSesC protein expressed in BL21 (DE3) after induction. B) Purification of recombinant protein based on the Ni- affinity process. Soluble 55KD protein was purified by affinity chromatography. Target protein eluted using $300 \mathrm{~mm}$ imidazole as an elution buffer followed by washing the non-specific proteins by $30-100 \mathrm{mMimidazol}$ as washing buffers. C) Reconfirmation of purified protein by specific antibodies to hexahistidin tail. E) Amplification of a 1399 bp sequence encoded rSesC protein, DNA ladder; 1: S. epidermidis ATTC 12228 confirmed by SesC primers and amplicon size is $388 \mathrm{bp}$; 2- 5: S. epidermidis wild type 10b. F) Digestion of the responsible gene for protein synthesis (1359 bp plus 40 bp restriction sites and hexa his sequence) by restriction enzymes in expression vector pET11C (M, DNA ladder; 5 , purified expression vector; 6 , single digestion by BamH1 enzyme: 4, single digested vector by Nhe1 Enzyme: 7, double digested expression vector by BamH1 and Nhe1 restriction enzymes, 8 , single digestion by Hindlll restriction enzyme. 


\section{PIA purification chromatogram}

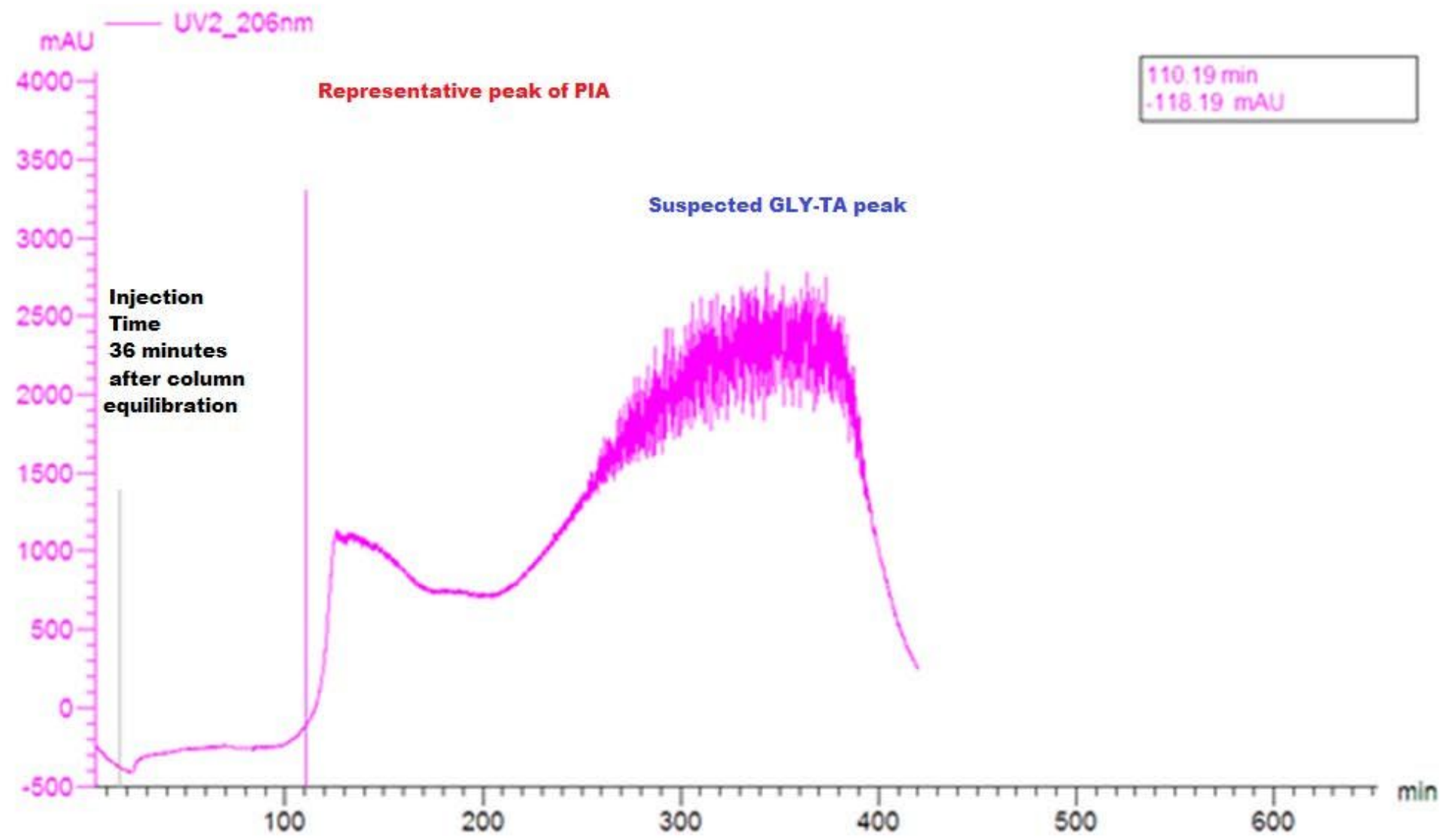

Figure 2

Purification of PIA. Representative Fast protein liquid chromatography (FPLC) chromatogram for native PIA. Sample in $1 \mathrm{ml}$ final volume was injected after 36 minutes column equilibration. PIA was eluted near the void volume following the 110 minutes after sample injection by using $0.3 \mathrm{ml} / \mathrm{min}$ flowrate. Polysaccharide was identified at a wavelength of $206 \mathrm{~nm}$ and protein was identified at $280 \mathrm{~nm}$. 
Hexosamine assay standard curve

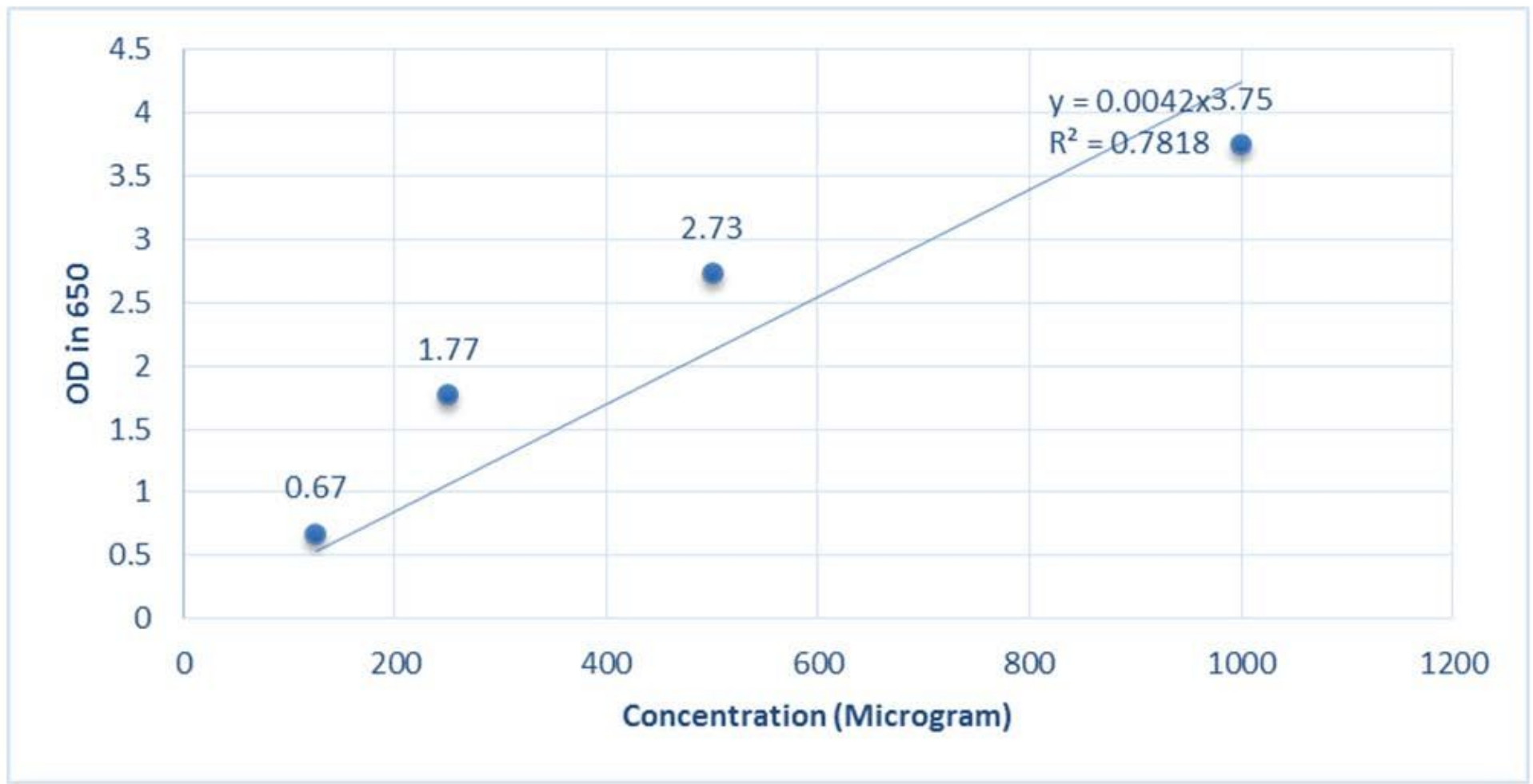

\section{Figure 3}

Standard curve to hexosamine assay. According to the procedure, three concentration $(\mu \mathrm{g} / \mathrm{ml})$ of Nacetylglucosamine as standard were used and optical density of these concentrations evaluated in 650 $\mathrm{nm}$. 


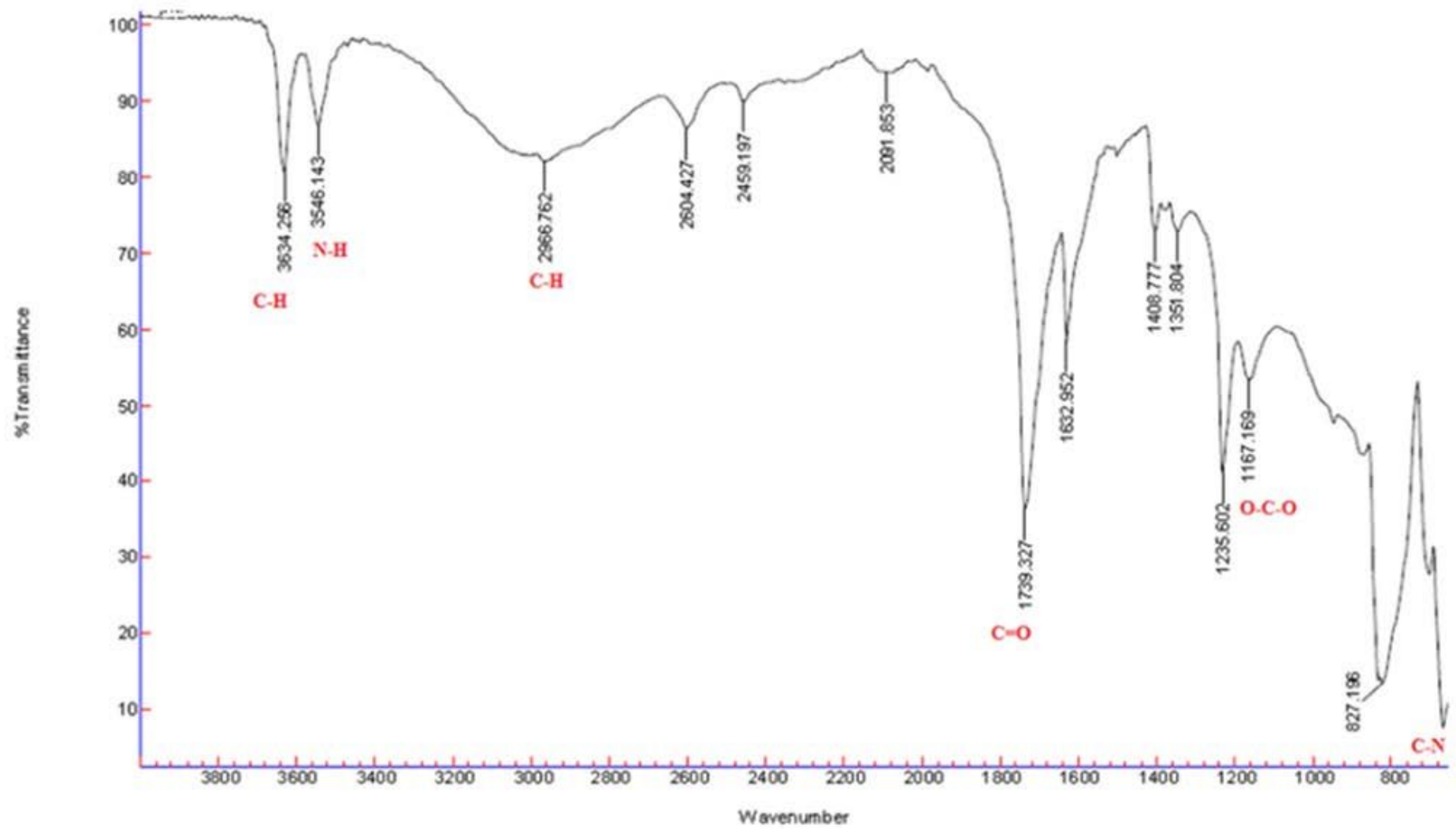

\section{Figure 4}

IR spectra of Purified PIA in the $4000-500 \mathrm{~cm}-1$ range and the result of this deconvolution. Infrared spectroscopy of purified polysaccharide was investigated using the regularized method of deconvolution. According to the composition of the PIA molecules $\mathrm{C}=0$ groups in 1739.327 of the native polysaccharide in the FTIR pattern, was detected. 


\section{Booster effect}

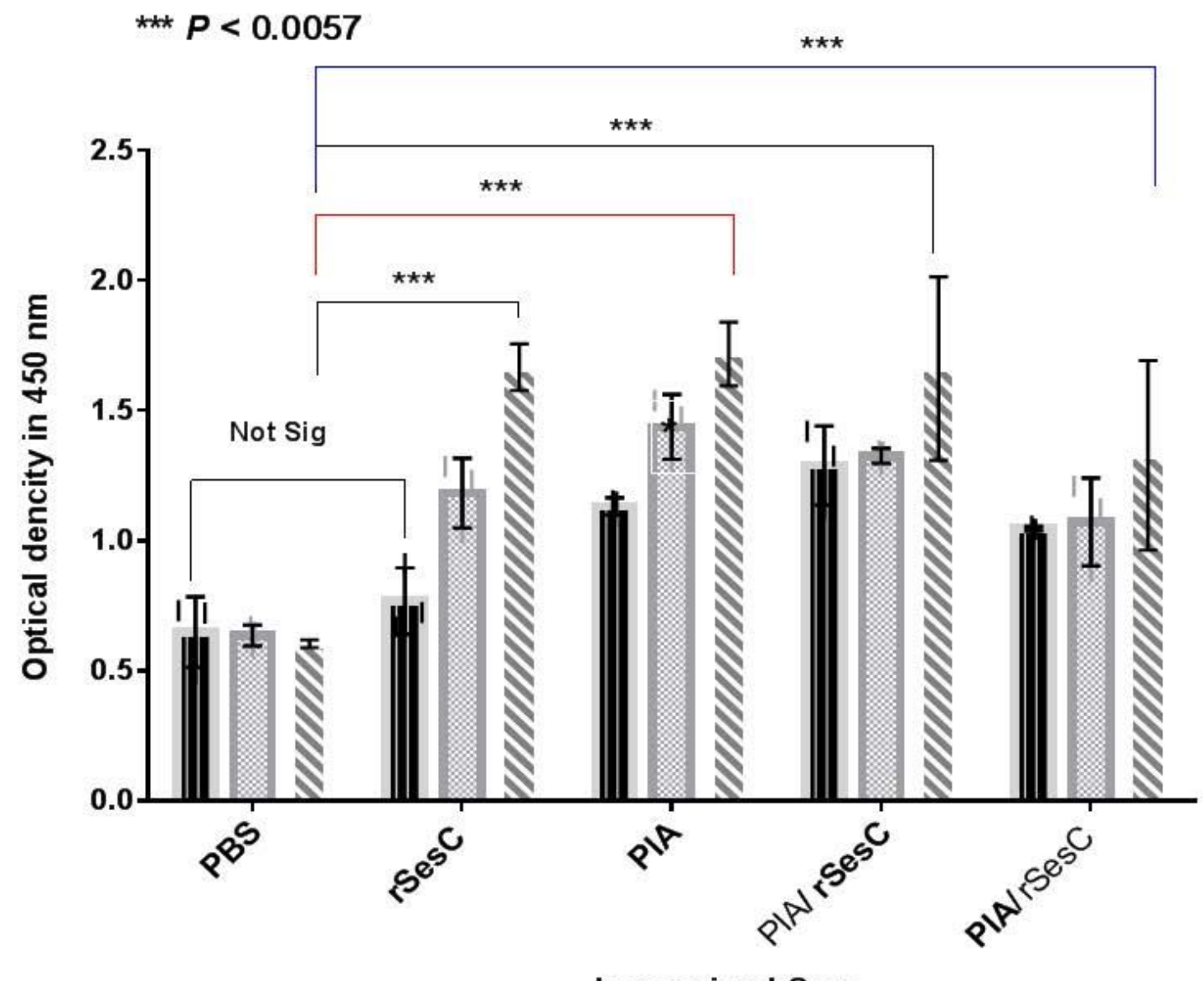

Days after first immunization

III days

28 days

42 days

Immunized Sera

Figure 5

Total arisen antibodies to antigens. The booster effect of the assessed antigens at different times. ELISA was performed by coating the native PIA and rSesC. The titers of the antibodies was assessed for immunized sera compared to the controls. Significant effects were observed from use of the mixture and conjugate booster. Six weeks after the first injection, the titres of antibodies had increased. Antibody titration was assessed in 1: 200 titer, the error bar is representative of the mean $\pm s d(n=3)$. 


\section{Biofilm inhibition assay}

** $P<0.0004$

* $P<0.05$

Days after first immunization

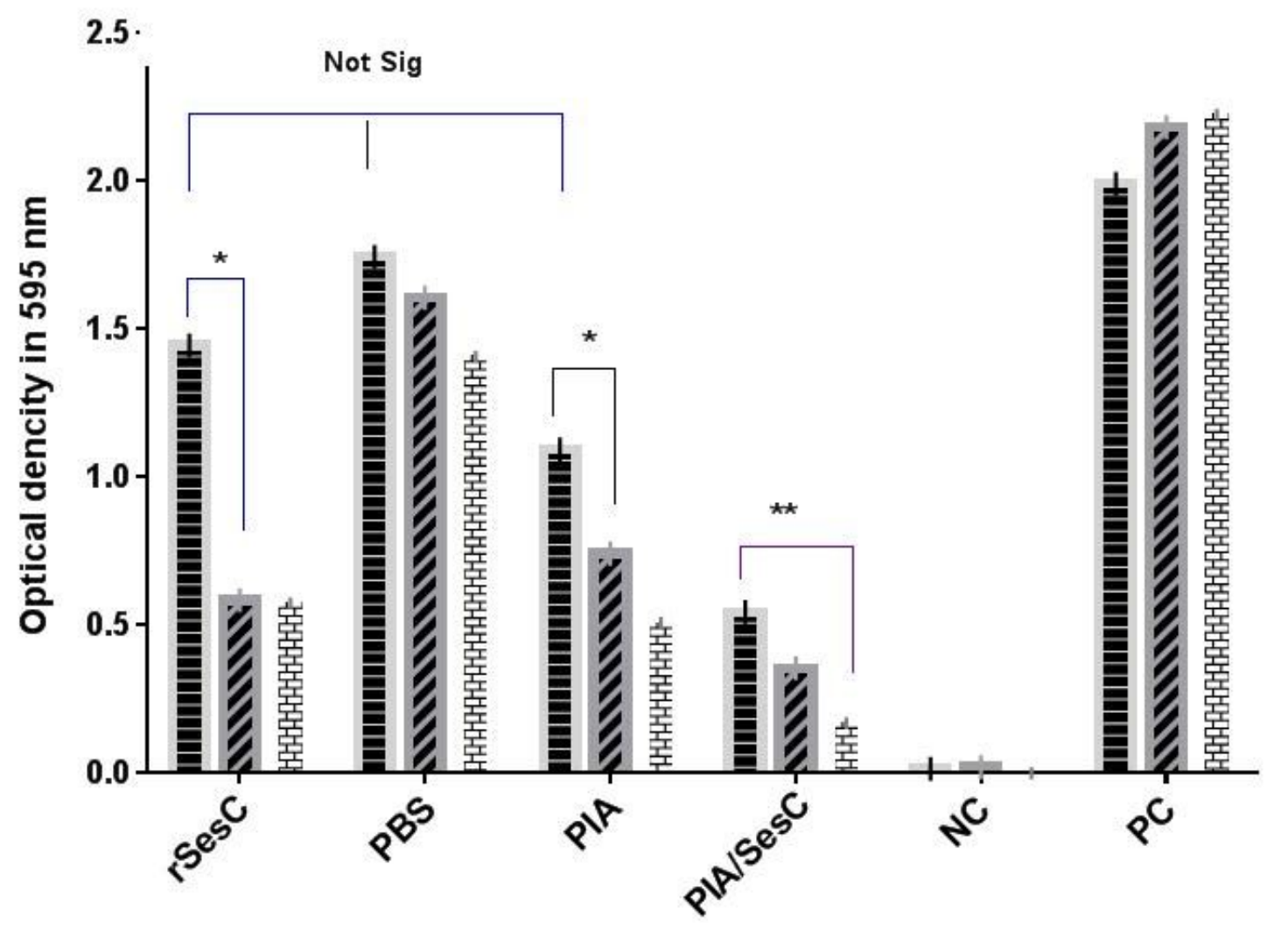

Immunized Sera

Figure 6

Biofilm inhibition assay by comparing diluted sera. The biofilm-inhibitory effects of increasing antibodies (after each shot) were determined by comparing the positive and negative controls using the mentioned formula. The error bar is representative of the mean $\pm s d(n=3)$.

\section{Supplementary Files}

This is a list of supplementary files associated with this preprint. Click to download.

- Table1.jpg

- NC3RsARRIVEGuidelinesChecklist.docx 